\title{
REPEATED POSITRON EMISSION TOMOGRAPHY- COMPUTED TOMOGRAPHY AND PERFUSION- COMPUTED TOMOGRAPHY IMAGING IN RECTAL CANCER: FLUORODEOXYGLUCOSE UPTAKE CORRESPONDS WITH TUMOR PERFUSION
}

Citation for published version (APA):

Janssen, M. H. M., Aerts, H. J. W. L., Buijsen, J., Lambin, P., Lammering, G., \& Ollers, M. C. (2012). REPEATED POSITRON EMISSION TOMOGRAPHY-COMPUTED TOMOGRAPHY AND PERFUSIONCOMPUTED TOMOGRAPHY IMAGING IN RECTAL CANCER: FLUORODEOXYGLUCOSE UPTAKE CORRESPONDS WITH TUMOR PERFUSION. International Journal of Radiation Oncology Biology Physics, 82(2), 849-855. https://doi.org/10.1016/j.jirobp.2010.10.029

Document status and date:

Published: 01/02/2012

DOI:

10.1016/j.jijrobp.2010.10.029

Document Version:

Publisher's PDF, also known as Version of record

Document license:

Taverne

Please check the document version of this publication:

- A submitted manuscript is the version of the article upon submission and before peer-review. There can be important differences between the submitted version and the official published version of record. People interested in the research are advised to contact the author for the final version of the publication, or visit the DOI to the publisher's website.

- The final author version and the galley proof are versions of the publication after peer review.

- The final published version features the final layout of the paper including the volume, issue and page numbers.

Link to publication

\footnotetext{
General rights rights.

- You may freely distribute the URL identifying the publication in the public portal. please follow below link for the End User Agreement:

www.umlib.nl/taverne-license

Take down policy

If you believe that this document breaches copyright please contact us at:

repository@maastrichtuniversity.nl

providing details and we will investigate your claim.
}

Copyright and moral rights for the publications made accessible in the public portal are retained by the authors and/or other copyright owners and it is a condition of accessing publications that users recognise and abide by the legal requirements associated with these

- Users may download and print one copy of any publication from the public portal for the purpose of private study or research.

- You may not further distribute the material or use it for any profit-making activity or commercial gain

If the publication is distributed under the terms of Article $25 \mathrm{fa}$ of the Dutch Copyright Act, indicated by the "Taverne" license above,

Download date: 26 Apr. 2023 


\title{
REPEATED POSITRON EMISSION TOMOGRAPHY-COMPUTED TOMOGRAPHY AND PERFUSION-COMPUTED TOMOGRAPHY IMAGING IN RECTAL CANCER: FLUORODEOXYGLUCOSE UPTAKE CORRESPONDS WITH TUMOR PERFUSION
}

\author{
Marco H. M. Janssen, M.Sc., Hugo J. W. L. Aerts, M.Sc., Jeroen Buijsen, M.D., \\ Philippe Lambin, M.D., Ph.D., Guido Lammering, M.D., Ph.D., and Michel C. Öllers, M.Sc., Ph.D. \\ Department of Radiation Oncology, Maastricht University Medical Center, Department of Radiation Oncology (MAASTRO), \\ GROW-School for Oncology and Developmental Biology, Maastricht University Medical Center, Maastricht, The Netherlands
}

\begin{abstract}
Purpose: The purpose of this study was to analyze both the intratumoral fluorodeoxyglucose (FDG) uptake and

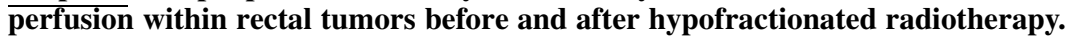

Methods and Materials: Rectal cancer patients, referred for preoperative hypofractionated radiotherapy (RT), underwent FDG-positron emission tomography (PET)-computed tomography (CT) and perfusion-CT (pCT) imaging before the start of hypofractionated RT and at the day of the last RT fraction. The pCT-images were analyzed using the extended Kety model, quantifying tumor perfusion with the pharmacokinetic parameters $K^{\text {trans }}$, $v_{e}$, and $v_{p}$. The mean and maximum FDG uptake based on the standardized uptake value (SUV) and transfer constant $\left(K^{\text {trans }}\right)$ within the tumor were correlated. Also, the tumor was subdivided into eight subregions and for each subregion the mean and maximum SUVs and $K^{\text {trans }}$ values were assessed and correlated. Furthermore, the mean FDG uptake in voxels presenting with the lowest $25 \%$ of perfusion was compared with the FDG uptake in the voxels with the $25 \%$ highest perfusion.

Results: The mean and maximum $K^{\text {trans }}$ values were positively correlated with the corresponding SUVs $(\rho=0.596$, $\overline{p=0.001}$ and $\rho=0.779, p<0.001)$. Also, positive correlations were found for $K^{\text {trans }}$ values and SUVs within the subregions (mean, $\rho=0.413, p<0.001$; and max, $\rho=0.540, p<0.001$ ). The mean FDG uptake in the $25 \%$ highest-perfused tumor regions was significantly higher compared with the $25 \%$ lowest-perfused regions $(10.6 \% \pm 5.1 \%, p=0.017)$. During hypofractionated radiotherapy, stable mean $(p=0.379)$ and maximum $(p=$ 0.280) FDG uptake levels were found, whereas the mean $(p=0.040)$ and maximum $(p=0.003) K^{\text {trans }}$ values were found to significantly increase.

Conclusion: Highly perfused rectal tumors presented with higher FDG-uptake levels compared with relatively low perfused tumors. Also, intratumor regions with a high FDG uptake demonstrated with higher levels of perfusion than regions with a relatively low FDG-uptake. Early after hypofractionated RT, stable FDG uptake levels were found, whereas tumor perfusion was found to significantly increase. (c) 2012 Elsevier Inc.
\end{abstract}

Perfusion-CT, FDG-PET-CT, Rectal cancer, Hypofractionated radiotherapy, Tumor perfusion, FDG uptake.

\section{INTRODUCTION}

Radiotherapy (RT), alone or with chemotherapy, is an established treatment for patients diagnosed with rectal cancer (1-3). The use of sequential positron emission tomography (PET) and perfusion-CT (pCT) imaging allows a closer look at therapy related changes of the tumor's metabolic activity and tumor perfusion, which might enable tumor response predictions and tailored therapies in the future (47). Evaluation of the metabolic activity of malignancies, assessed with sequential fluorodeoxyglucose (FDG)-PET imaging, has been shown to be an accurate and promising method for the prediction of treatment response during and after neoadjuvant radiochemotherapy (RCT) in an increasing number of malignancies (5, 8-19). The response index (RI), describing the percentage of reduction of maximum standardized uptake value $\left(\mathrm{SUV}_{\max }\right)$ after 2 weeks of preoperative RCT treatment, has been presented as an accurate predictor of the pathological treatment response (5, 16-19). Also, tumors with higher FDG uptake level before the start of treatment presented with a higher
Reprint requests to: Marco H.M. Janssen, M.Sc., MAASTRO Clinic, Dr. Tanslaan 12, 6201 BN Maastricht, Box 1588, the Netherlands. Tel: +31(0)884455779; Fax: +31(0)884455667; E-mail: marco.janssen@maastro.nl

G. Lammering and M.C. Öllers contributed equally to this study.

Conflict of interest: none.

Acknowledgments-The authors acknowledge financial support from the Netherlands Organization for Health Research and Devel- opment (ZonNW; clinical fellowship awarded to G.L.) and the Dutch Cancer Society (KWF: fellowship awarded to H.J.W.L.A.). We also acknowledge technical and financial support from Siemens MI.

Received June 28, 2010, and in revised form Sept 8, 2010. Accepted for publication Oct 6, 2010. 
decrease in the SUVs early during treatment compared with tumors with a lower pretreatment FDG uptake $(18,19)$. Therefore, an accurate prediction of the pathological tumor response already early during preoperative treatment would enable more individualized treatment regimens, aiming at further improvement of the tumor response or a modified surgical approach.

Except changes in the metabolic activity of the tumor, assessments of the microvascular status of the tumor tissue using pCT measurements have also been presented as an early marker of treatment response (20-24). pCT Imaging is increasingly applied to noninvasively assess the microvascular status of tumor tissue by studying the uptake kinetics of the administered tracer over time (7, 20-23, 25-34). A two-compartment model (extended Kety model) is commonly used for pharmacokinetic modeling of the tracer's uptake kinetics, quantifying tumor perfusion with the pharmacokinetic parameters $K^{\text {trans }}, \mathrm{v}_{\mathrm{e}}$, and $\mathrm{v}_{\mathrm{p}}(35$, 36). For perfusion measurements, $K^{\text {trans }}$, describing the transfer rate of the used tracer from the blood plasma into the extravascular-extracellular space (EES), is the most valuable pharmacokinetic parameter related to the microvascular blood flow, vessel wall permeability, and vessel density (36). Malignancies presenting with a high $\mathrm{K}^{\text {trans }}$ value before treatment tend to better respond to (radio)chemotherapy treatment compared with tumors with relatively low values of $K^{\text {trans }}(20-24,32-34)$.

The purpose of this study was to analyze the intratumoral FDG uptake and perfusion within rectal tumors before and after hypofractionated radiotherapy, as well as to test a possible correlation between the tumor's metabolic activity and tumor perfusion.

\section{METHODS AND MATERIALS}

\section{Patient characteristics}

Patients diagnosed with non-locally advanced rectal cancer and scheduled for preoperative radiotherapy treatment followed by surgery were considered for study enrollment. For each included patient, the TNM stage was determined from pretreatment magnetic resonance (MR) images. All patients were preoperatively referred to short-course hypofractionated RT, five fractions of $5 \mathrm{~Gy}$ on 5 consecutive working days, followed by a total mesorectal excision (TME) within 3 days after the last RT fraction. According to the Dutch law, the medical ethics committee approved the trial, and all patients gave written informed consent before entering the study.

\section{PET-CT and $p C T$ acquisition}

All patients underwent a FDG-PET-CT scan combined with a pCT scan before the start of treatment and at the day of the last RT fraction. All PET-CT and pCT examinations were performed on the same dedicated Siemens TruePoint Biograph 40 PET-CT simulator (Siemens Medical, Erlangen, Germany). The patients were positioned equal to the radiotherapy treatment position using a laser alignment system to have minimal variations between imaging and treatment conditions and between the two imaging time points. After a fasting period of at least $6 \mathrm{~h}$, patients received an intravenous injection of FDG, with the activity normalized for the patients' body weight (weight $[\mathrm{kg}] * 4+20$ [MBq]). Static PET acquisition was started after an uptake period of
$60 \mathrm{~min}$, with an acquisition time of $5 \mathrm{~min}$ per bed position. For PET reconstruction (OSEM2D: four iterations, 8 subsets), CT based attenuation correction and three-dimensional scatter and decay correction were performed. After the PET-CT scan, a pCT-scan was performed over $100 \mathrm{~s}$. The field-of-view (FOV) for the pCT scan was defined by an expert radiation oncologist (J.B. or G.L.) with knowledge of the PET data. To ensure that the most representative tumor area was chosen, the tumor area with the highest FDG-uptake on the PET scan was selected. Knowledge of the FOV selected for the first pCT scan was used to select the identical region for the second pCT scan. For the pCT-scan, $120 \mathrm{ml}$ of an iodinated contrast-agent (300 mg iodine/ ml; Xenetix 300, Guerbet, Aulnay-sous-Bois, France) was injected at a rate of $3 \mathrm{ml} / \mathrm{s}$ via an automatic injector (Stellant Sx, CT Injection System, MedRad, Warrendale, PA) into the antecubital fossa. The pCT-scan was performed in a static cine-mode over 12 contiguous slices with a slice thickness of $2.4 \mathrm{~mm}$, a FOV of $500 \mathrm{~mm}$, and an image size of $512 \times 512$ pixels. Other acquisition settings were tube voltage $80 \mathrm{kVp}$, tube current $140 \mathrm{mAs}$, and a rotation time of $1 \mathrm{~s}$.

\section{PET analysis and tumor contouring}

For each of the PET scans, a tumor contour was generated using automated SUV thresholding with the threshold (percentage of $\mathrm{SUV}_{\max }$ within the tumor) depending on the tumor-tobackground signal ratio with the gluteus muscle selected as relevant background $(37,38)$. Dedicated software (TrueD, Siemens Medical, Erlangen, Germany) was used to calculate the mean and maximum FDG uptake (SUV) within the tumor. In addition, all PET data were normalized for the blood-glucose-level (BGL) measured shortly before FDG administration $(19,39,40)$.

\section{pCT Analysis}

Image-registration between the PET-CT scan and the pCT-scan was performed using a registration algorithm based on Mutual Information (Focal software, version 4.34, CMS Inc., St. Louis, MO). The automatic tumor delineation based on PET thresholding was exported and projected onto the $\mathrm{pCT}$ dataset for further analysis. The $\mathrm{pCT}$ images were down-sampled from a voxel size of $0.98 \times$ $0.98 \times 2.4 \mathrm{~mm}$ to $3.92 \times 3.92 \times 4.8 \mathrm{~mm}$ to improve the signalto-noise ratio. For the quantification of the dynamic pCT data, the extended Kety model was used, describing the uptake of a contrast agent from the blood plasma into the tissue by (36):

$$
C_{t}(t)=v_{p} C_{p}(t)+K^{t r a n s} \int_{0}^{t} C_{p}(u) e^{-\frac{-K_{\text {trans }}}{v_{e}}(t-u)} d u
$$

The blood plasma concentration curve $\left(C_{p}\right)$, extracted from the right external iliac artery, was derived from the acquired whole blood tracer concentration $\left(C_{b}\right)$ divided by $(1-\mathrm{Hct})$, with the hematocrit value (Hct) set to 0.45 (36). To improve the signal-to-noise ratio, $C_{p}$ was calculated by averaging the concentration time curves over all voxels selected inside the iliac artery. The tumor concentration curves $\left(C_{t}\right)$ were extracted from the dynamic $\mathrm{pCT}$ data on a voxelby-voxel basis and on a tumor uptake curve based on the average of all tumor voxels. Pharmacokinetic analysis was performed using in-house-developed software (MATLAB, R2008b, Mathworks, Natick, MA). The concentration time curves from $\mathrm{pCT}$-data were fitted to the pharmacokinetic model, with the pharmacokinetic parameters being calculated using the Levenberg-Marquardt algorithm, with boundaries set to $0 \leq K^{\text {trans }} \leq 5 \mathrm{~min}^{-1}, 0 \leq v_{e} \leq 1$ and $0 \leq v_{p} \leq 1$ (41-43). 


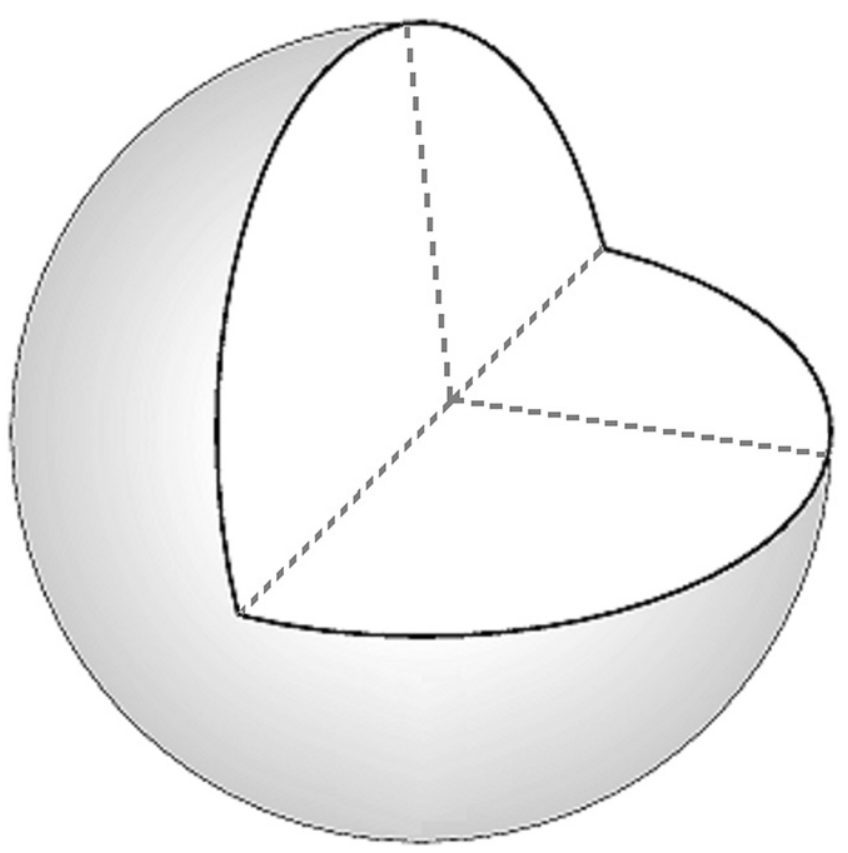

Fig. 1. Spherical representation of a tumor with the dashed lines indicating the cutting planes used for subdivision of the tumor into 8 subregions.

\section{Correlation of FDG uptake and tumor perfusion}

For each of the included patients, the mean and maximum FDG uptake (SUV) and transfer constant $\left(K^{\text {trans }}\right)$ within the tumor were correlated. Next, based on the tumor contour resulting from SUV thresholding, the tumor was subdivided into eight subregions (Fig. 1). For each of the tumor subregions, the mean and maximum SUVs and $K^{\text {trans }}$ values were assessed and correlated.

In addition, the mean FDG uptake in the voxels presenting with the lowest $25 \%$ of perfusion ( $K^{\text {trans }}$ values) was compared with the FDG uptake in the voxels with the $25 \%$ highest perfusion.

To study early treatment effects, the metabolic activity of the tumors as well as the level of tumor perfusion were studied over time by comparing the pre- and posttreatment scans.

\section{Statistical analysis}

Statistical differences between parameters were evaluated in SPSS version 15.0 (SPSS Inc., Chicago, IL), performing a Wilcoxon signed-rank test for the comparison of related measurements. Differences were considered to be significant when the $p$ value was less than 0.05 . For assessing the correlation between FDG uptake perfusion within the tumor, the Spearman's rank coefficient $(\rho)$ was calculated.

\section{RESULTS}

\section{Patient characteristics}

Twenty patients (mean age, $67.0 \pm 10.9$ years) diagnosed with non-locally advanced rectal cancer were included in this study. Based on pretreatment MR imaging (MRI), the clinical TNM staging was staged as T 1-3, N 0-1, M 0-1. For 3 of the included patients, large deformations of the rectum were observed when registering the CT and pCT scan. As these large deformations hamper an accurate registration of the PET-CT and pCT scans, a reliable correlation of the FDG uptake within and perfusion of the tumor could not be ensured. For this reason, 17 patients remained for further analysis.

\section{Correlation of the metabolic activity and perfusion of rectal tumors}

In Fig. 2, a FDG-PET-CT and pCT scan of a representative patient is shown. Visual inspection shows that there is a large correspondence of FDG uptake and perfusion within the tumor. Note the heterogeneous pattern of both the FDG uptake and perfusion of the tumor. When comparing the mean and maximum SUVs and $K^{\text {trans }}$ values within the tumors of the included patients, clear relationships were found with correlation coefficients $(\rho)$ of respectively $0.596(p=0.001)$ and 0.779 ( $p<0.001)$ (Fig. 3).

A location-based analysis was performed by subdividing the tumors into eight sub-regions and comparing the FDG uptake and perfusion within these regions. The mean and maximum $K^{\text {trans }}$ values and SUVs showed a large correspondence, with positive correlation coefficients $(\rho)$ of $0.413(p<$ $0.001)$ and $0.540(p<0.001)$, respectively (Fig 4). Furthermore, the pretreatment measured mean FDG uptake of the voxels within the tumor presenting with the $25 \%$ highest

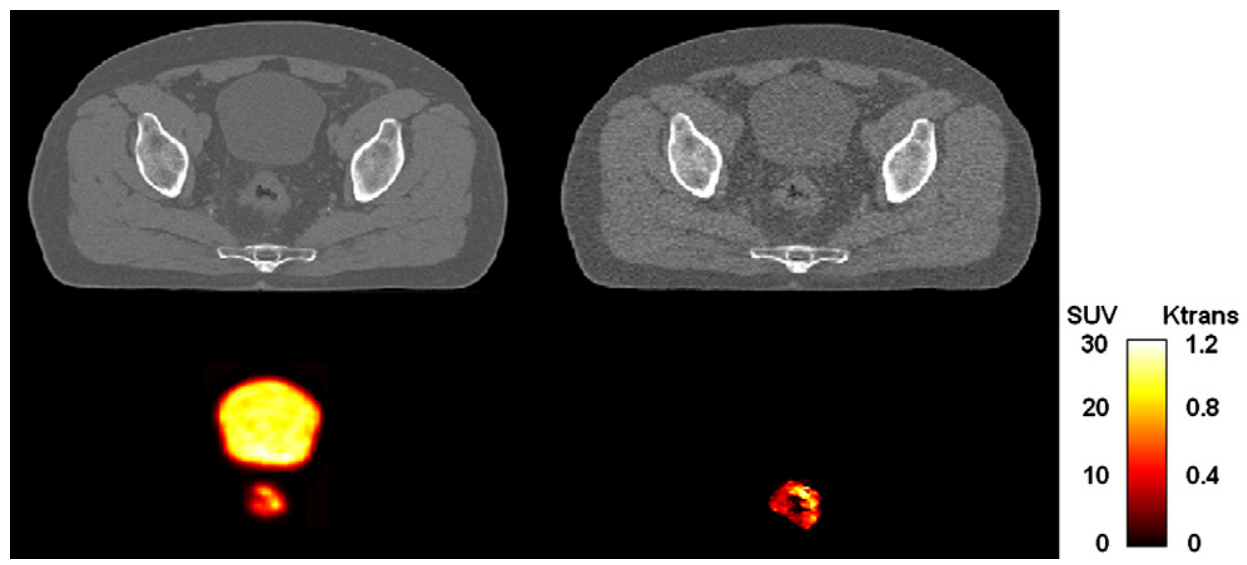

Fig. 2. Pre-treatment comparison of a positron emission tomography-computed tomography (PET-CT) image (left) and a perfusion-computed tomography (pCT) image and the corresponding $K^{\text {trans }}$ map (right). 

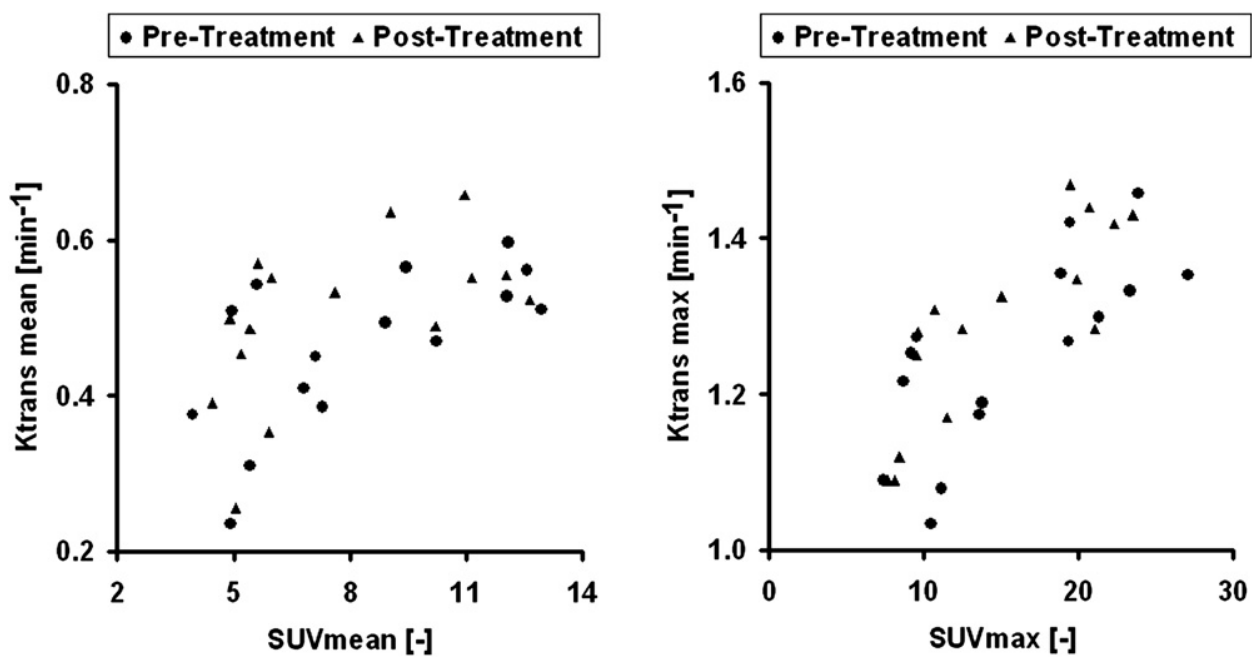

Fig. 3. Scatter plots of the mean and maximum FDG uptake (SUV) within the tumor and the mean and maximum tumor perfusion ( $K^{\text {trans }}$ values). Note the positive correlation between the FDG uptake within and perfusion of tumor tissue for both the pre- and post-treatment situation.

$K^{\text {trans }}$ values was found to be significantly higher compared with the FDG uptake of the voxels within the tumor presenting with the $25 \%$ lowest $K^{\text {trans }}$ values. For the $25 \%$ highest perfused tumor voxels, a $10.6 \% \pm 5.1 \%(p=0.017)$ higher mean SUVs were found when compared with the $25 \%$ lowest perfused tumor voxels (Fig. 5).

\section{Hypofractionated radiotherapy treatment effect}

To study the early effects of hypofractionated radiotherapy on the FDG uptake within and perfusion of rectal tumors, PET-CT and pCT scans were performed before the start of treatment and at the day of the last radiotherapy fraction. When comparing the mean (pre, $7.9 \pm 3.0$; post, $7.5 \pm$ 2.8; $p=0.362$ ) and maximum (pre, $15.8 \pm 6.4$; post, $14.6 \pm$ 5.8; $p=0.280$ ) SUVs, stable FDG uptake levels were found during short-course hypofractionated RT (44). However, for the mean (pre, $0.463 \pm 0.102 \mathrm{~min}^{-1}$; post, $0.500 \pm 0.105$ $\left.\min ^{-1} ; p=0.040\right)$ and maximum (pre, $1.253 \pm 0.124$ $\min ^{-1}$; post, $\left.1.340 \pm 0.092, \min ^{-1}, p=0.003\right) K^{\text {trans }}$ values, significant increases were found between both pCT scans (7). In Fig. 6, the average histograms of the $K^{\text {trans }}$ values and SUVs within the tumor are shown for all patients. As can be seen from the histograms, preoperative treatment with hypofractionated RT resulted in an increased tumor perfusion for the included patients, whereas stable FDG uptake levels were found. For the bins of the histogram presenting the number of voxels with a relatively high $K^{\text {trans }}$ value, an increase of the number of voxels was observed between the pre- and posttreatment pCT scan. In contradiction, a decrease was found for the number of voxels in the bins with a lower $K^{\text {trans }}$ value. The shift of the histogram toward increased bins with relatively higher $K^{\text {trans }}$ indicates an increase of tumor perfusion because of preoperative treatment with short-course hypofractionated RT.
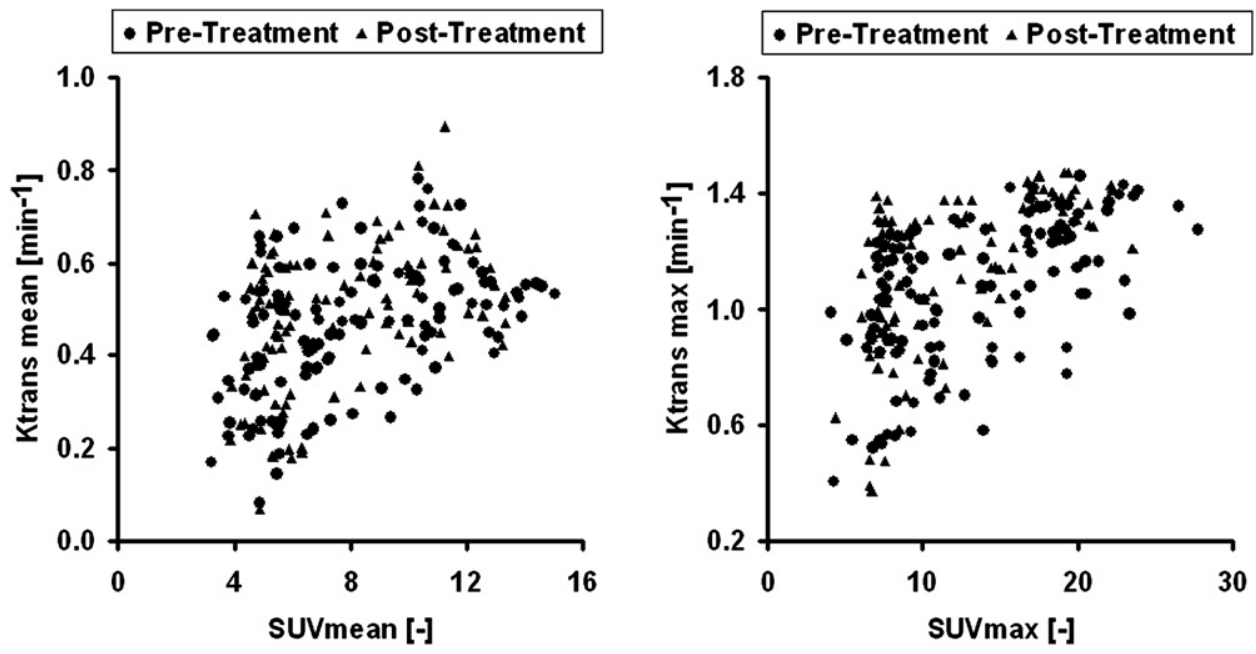

Fig. 4. Scatter plots of the FDG uptake (SUV) and perfusion ( $K^{\text {trans }}$ values) within the eight created tumor sub-regions for a location based analysis. Each dot or triangle represents the FDG uptake within and perfusion of one of the eight subregions created within a patient's rectal tumor respectively before and after treatment. 


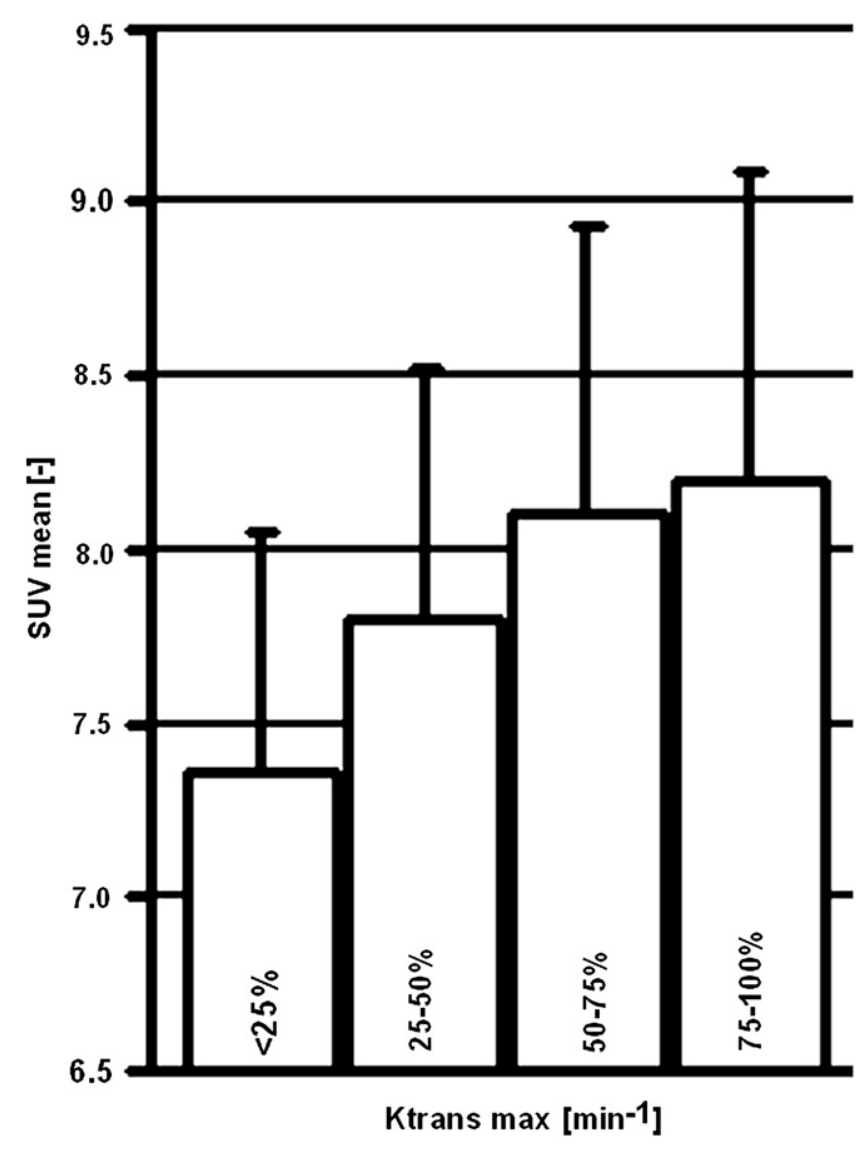

Fig. 5. For the pretreatment situation, a significant higher FDG uptake was observed within the tumor voxels presenting with the $25 \%$ highest $K^{\text {trans }}$ values when compared with the voxels presenting with the $25 \%$ lowest $K^{\text {trans }}$ values.

\section{DISCUSSION}

The purpose of this study was to analyze the intratumoral FDG uptake within and perfusion of rectal tumors before and after hypofractionated radiotherapy treatment as well as to test a possible correlation between FDG uptake and tumor perfusion. The FDG uptake within rectal tumors was found to positively correlate with tumor perfusion assessed from dynamic pCT images. Highly perfused rectal tumors presented with higher FDG uptake levels compared with relatively low perfused tumors. To our knowledge, this article is the first to describe a positive correlation of FDG-PET and $\mathrm{pCT}$ imaging for rectal cancer. The presented findings for rectal cancer patients are in line with the findings of Miles $\mathrm{et} \mathrm{al}$. and Groves et al. for lung and breast cancer patients, respectively $(25,27,28)$. Patients diagnosed with a relatively high perfused tumor tend to better respond to (radio)chemotherapy when compared with relatively low perfused tumors $(20-24,32,33)$. Based on the presented results, it could be suggested that, for highly perfused tumors, a better distribution of the administered FDG, and possibly also of a chemotherapeutic drug, is possible. However, for different types of malignancies, FDG uptake has been studied as a surrogate marker for the detection and imaging of hypoxia, although with conflicting findings (45-47). The results presented here, specifically, a strong positive correlation between FDG uptake and tumor perfusion, are in conflict with an increased FDG uptake as a surrogate marker of tumor hypoxia, as tumors are thought to develop hypoxia because of a low perfusion.

Another finding of this study was the difference in early treatment response as measured with respectively PET and pCT imaging. Early during hypofractionated RT, the mean and maximum FDG uptake levels within the tumors were found to be stable, whereas the mean and maximum $K^{\text {trans }}$ values were found to increase significantly. The significant increase of the mean and maximum $K^{\text {trans }}$ values early during preoperative RT could be caused by endothelial cell death within the tumor, stress reactions of injured tumor cells, or even death of tumor cells resulting from the hypofractionated RT treatment (48). Endothelial cell death would result in endothelial cell leakage, which in turn results in increased $K^{\text {trans }}$ values within the tumor.

Because of the relative small dimension of the FOV for pCT imaging of the used PET-CT simulator in the craniocaudal dimension (only $2.88 \mathrm{~cm}$ ), the craniocaudal coverage of the FOV resulted in incomplete tumor coverage in some patients. Because of the possibly incomplete tumor coverage,
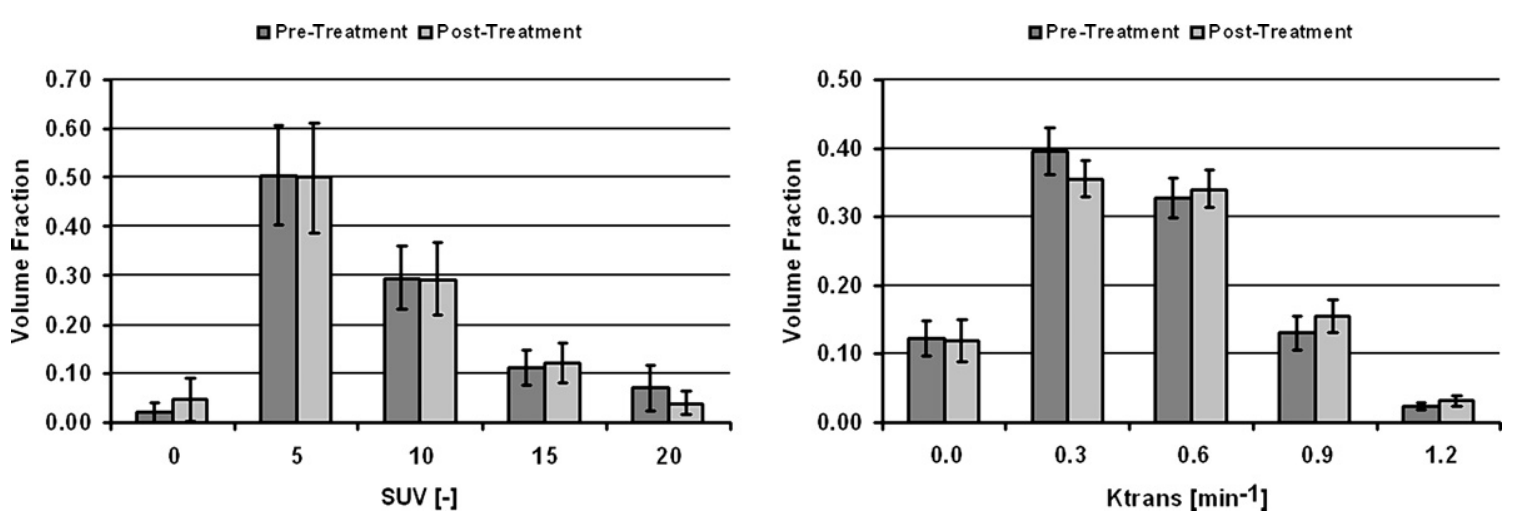

Fig. 6. Treatment effect of hypofractionated radiotherapy on both the FDG uptake within and perfusion of rectal tumors. For the FDG uptake within rectal tumors, no significant treatment effect was observed, whereas a shift towards an overall better tumor perfusion was observed when evaluating the $K^{\text {trans }}$ values. 
the calculated mean $K^{\text {trans }}$ values represent the perfusion of the tissue covered by the FOV. However, Goh et al. presented a study showing that an increase in the FOV in craniocaudal direction did not improve the reproducibility of perfusion measurements (29). Nevertheless, current state-of-the-art (PET)-CT scanners are becoming available that are able to perform volumetric perfusion measurements that encompass the entire tumor volume.

The major limitation of sequential functional imaging (PET and pCT imaging), followed by a voxelwise comparison of the resulting images, are deformations of the organs within the scanned region of the human body. Not only day-to-day differences in bladder and rectum filling, but also differences in bladder and rectum filling and bowel peristalsis within the short time span (maximum $20 \mathrm{~min}$ ) between the PET-CT and $\mathrm{pCT}$ scan hampered an accurate voxelwise comparison of the PET and pCT images. Because of this, for this study, only a region-based comparison of FDG uptake within and perfusion of tumor tissue was performed. Even for the region-based correlation of the FDG uptake level and tumor perfusion, an accurate registration of the PET-CT and pCT images should be ensured. Three of the included patients were excluded from further analysis because of large deformations of the rectum between the PET-CT and pCT scan.

Within a recent study, we presented pCT imaging as an alternative modality to Dynamic contrast-enhanced magnetic resonance imaging (MRI) for the in vivo evaluation of tumor perfusion in terms of the transfer constant $\mathrm{K}^{\text {trans }}$ (31). Because of the relatively high availability of CT scanners over MRI scanners within radiotherapy departments, as well as the shorter total examination duration of a pCT scan, pCT imaging is an attractive alternative for DCEMRI imaging. Also, pCT imaging has a better time resolution compared with DCE-MRI imaging, which enables a high temporal acquisition of the first pass of the administered tracer. However, each pCT scan results in an additional effective dose of $15 \mathrm{mSv}$, whereas DCE-MRI can be performed without ionizing radiation. However, all of the included patients were scheduled for preoperative treatment with short-course hypofractionated radiotherapy. The additional effective dose caused by pCT scanning should be compared with the much higher dose planned to preoperatively treat the patient, as well as to the relatively advanced age and the life expectations of the patients. For relatively young patients and/or when a MRI system is available, DCE-MRI is recommended over pCT imaging because of the better signal-to-noise characteristics, stronger contrast uptake, larger tumor coverage, and the absence of ionizing-radiation.

\section{CONCLUSION}

In conclusion, FDG uptake within the tumor, assessed with PET imaging, was found to positively correlate with tumor perfusion assessed with dynamic pCT imaging. Highly perfused rectal tumors presented with higher FDG uptake levels compared to relatively low perfused tumors. Early during hypofractionated radiotherapy, tumor perfusion was already found to significantly increase, whereas FDG uptake levels were stable over time. Thus, for highly perfused rectal tumors or regions within the tumor, a better distribution of the administered FDG is more likely compared with tumors with a relatively low perfusion.

\section{REFERENCES}

1. Frykholm G, Glimelius B, Pahlman L. Preoperative irradiation with and without chemotherapy (MFL) in the treatment of primarily non-resectable adenocarcinoma of the rectum. Results from two consecutive studies. Eur J Cancer Clin Oncol 1989;25:1535-1541.

2. Sauer R, Becker H, Hohenberger W, et al. Preoperative vs. postoperative chemoradiotherapy for rectal cancer. $N$ Engl $J$ Med 2004;351:1731-1740.

3. Sebag-Montefiore D. Developments in the use of chemoradiotherapy in rectal cancer. Colorectal Dis 2006;8(Suppl 3):14-17.

4. Dinter DJ, Horisberger K, Zechmann C, et al. Can dynamic MR imaging predict response in patients with rectal cancer undergoing cetuximab-based neoadjuvant chemoradiation? Onkologie 2009;32:86-93.

5. Hindie E, Hennequin C, Moretti JL. Predicting response to chemoradiotherapy in rectal and oesophageal cancer with 18F-FDG: Prognostic value and possible role in patient management. Eur J Nucl Med Mol Imaging 2007;34:1576-1582.

6. de Geus-Oei LF, Vriens D, van Laarhoven HW, et al. Monitoring and predicting response to therapy with 18F-FDG PET in colorectal cancer: A systematic review. J Nucl Med 2009; 50(Suppl 1):43S-54S.

7. Janssen MH, Aerts HJ, Kierkels RG, et al. Tumor perfusion increases during hypofractionated short-course radiotherapy in rectal cancer: Sequential perfusion-CT findings. Radiother Oncol 2010;94:156-160.
8. Capirci C, Rampin L, Erba PA, et al. Sequential FDG-PET/CT reliably predicts response of locally advanced rectal cancer to neo-adjuvant chemo-radiation therapy. Eur J Nucl Med Mol Imaging 2007;34:1583-1593.

9. Capirci C, Rubello D, Chierichetti F, et al. Long-term prognostic value of $18 \mathrm{~F}-\mathrm{FDG}$ PET in patients with locally advanced rectal cancer previously treated with neoadjuvant radiochemotherapy. AJR Am J Roentgenol 2006;187:W202208.

10. Vliegen RF, Beets-Tan RG, Vanhauten B, et al. Can an FDGPET/CT Predict Tumor Clearance of the Mesorectal Fascia after Preoperative Chemoradiation of Locally Advanced Rectal Cancer? Strahlenther Onkol 2008;184:457-464.

11. Kalff V, Duong C, Drummond EG, et al. Findings on 18F-FDG PET scans after neoadjuvant chemoradiation provides prognostic stratification in patients with locally advanced rectal carcinoma subsequently treated by radical surgery. J Nucl Med 2006;47:14-22.

12. Amthauer H, Denecke T, Rau B, et al. Response prediction by FDG-PET after neoadjuvant radiochemotherapy and combined regional hyperthermia of rectal cancer: Correlation with endorectal ultrasound and histopathology. Eur J Nucl Med Mol Imaging 2004;31:811-819.

13. Denecke T, Rau B, Hoffmann KT, et al. Comparison of CT, MRI and FDG-PET in response prediction of patients with locally advanced rectal cancer after multimodal preoperative 
therapy: Is there a benefit in using functional imaging? Eur Radiol 2005;15:1658-1666.

14. Guillem JG, Moore HG, Akhurst T, et al. Sequential preoperative fluorodeoxyglucose-positron emission tomography assessment of response to preoperative chemoradiation: A means for determining longterm outcomes of rectal cancer. J Am Coll Surg 2004;199:1-7.

15. Melton GB, Lavely WC, Jacene HA, et al. Efficacy of preoperative combined 18-fluorodeoxyglucose positron emission tomography and computed tomography for assessing primary rectal cancer response to neoadjuvant therapy. J Gastrointest Surg 2007;11:961-969, discussion 969.

16. Cascini GL, Avallone A, Delrio P, et al. 18F-FDG PET is an early predictor of pathologic tumor response to preoperative radiochemotherapy in locally advanced rectal cancer. J Nucl Med 2006; $47: 1241-1248$.

17. Rosenberg R, Herrmann K, Gertler R, et al. The predictive value of metabolic response to preoperative radiochemotherapy in locally advanced rectal cancer measured by PET/CT. Int J Colorectal Dis 2009;24:191-200.

18. Janssen MH, Ollers MC, Riedl RG, et al. Accurate prediction of pathological rectal tumor response after two weeks of preoperative radiochemotherapy using (18)F-fluorodeoxyglucose-positron emission tomography-computed tomography imaging. Int J Radiat Oncol Biol Phys 2010;77:392-399.

19. Janssen MH, Ollers MC, Stiphout RG, et al. Blood glucose level normalization and accurate timing improves the accuracy of PET-based treatment response predictions in rectal cancer. Radiother Oncol 2010;95:203-208.

20. Sahani DV, Kalva SP, Hamberg LM, et al. Assessing tumor perfusion and treatment response in rectal cancer with multisection CT: Initial observations. Radiology 2005;234:785-792.

21. Bellomi M, Petralia G, Sonzogni A, et al. CT perfusion for the monitoring of neoadjuvant chemotherapy and radiation therapy in rectal carcinoma: Initial experience. Radiology 2007;244: 486-493.

22. Park MS, Klotz E, Kim MJ, et al. Perfusion CT: Noninvasive surrogate marker for stratification of pancreatic cancer response to concurrent chemo- and radiation therapy. Radiology 2009;250:110-117.

23. Wang J, Wu N, Cham MD, Song Y. Tumor response in patients with advanced non-small cell lung cancer: Perfusion CT evaluation of chemotherapy and radiation therapy. AJR Am J Roentgenol 2009;193:1090-1096.

24. Zima A, Carlos R, Gandhi D, et al. Can pretreatment CT perfusion predict response of advanced squamous cell carcinoma of the upper aerodigestive tract treated with induction chemotherapy? AJNR Am J Neuroradiol 2007;28:328-334.

25. Groves AM, Wishart GC, Shastry M, et al. Metabolic-flow relationships in primary breast cancer: Feasibility of combined PET/dynamic contrast-enhanced CT. Eur J Nucl Med Mol Imaging 2009;36:416-421.

26. Miles KA. Perfusion CT for the assessment of tumour vascularity: Which protocol? Br J Radiol 2003;76(Spec No 1):S36S42.

27. Miles KA, Griffiths MR, Fuentes MA. Standardized perfusion value: Universal CT contrast enhancement scale that correlates with FDG PET in lung nodules. Radiology 2001;220:548-553.

28. Miles KA, Griffiths MR, Keith CJ. Blood flow-metabolic relationships are dependent on tumour size in non-small cell lung cancer: A study using quantitative contrast-enhanced computer tomography and positron emission tomography. Eur J Nucl Med Mol Imaging 2006;33:22-28.

29. Goh V, Halligan S, Gartner L, et al. Quantitative colorectal cancer perfusion measurement by multidetector-row CT: Does greater tumour coverage improve measurement reproducibility? Br J Radiol 2006;79:578-583.
30. Harvey C, Dooher A, Morgan J, et al. Imaging of tumour therapy responses by dynamic CT. Eur J Radiol 1999;30:221-226.

31. Kierkels RG, Backes WH, Janssen MH, et al. Comparison between perfusion computed tomography and dynamic contrastenhanced magnetic resonance imaging in rectal cancer. Int $J$ Radiat Oncol Biol Phys 2010;77:400-408.

32. Hermans R, Lambin P, Van der Goten A, et al. Tumoural perfusion as measured by dynamic computed tomography in head and neck carcinoma. Radiother Oncol 1999;53:105-111.

33. Hermans R, Van den Bogaert W. Outcome prediction after surgery and chemoradiation of head-and-neck squamous cell carcinoma (HNSCC), using baseline perfusion computed tomography (CT) microcirculatory parameters vs. tumor volume. Int J Radiat Oncol Biol Phys 2009;74:1307, author reply 1307.

34. Hayano K, Shuto K, Koda K, et al. Quantitative measurement of blood flow using perfusion CT for assessing clinicopathologic features and prognosis in patients with rectal cancer. Dis Colon Rectum 2009;52:1624-1629.

35. Aerts HJ, van Riel NA, Backes WH. System identification theory in pharmacokinetic modeling of dynamic contrastenhanced MRI: Influence of contrast injection. Magn Reson Med 2008;59:1111-1119.

36. Tofts PS, Brix G, Buckley DL, et al. Estimating kinetic parameters from dynamic contrast-enhanced T(1)-weighted MRI of a diffusable tracer: Standardized quantities and symbols. J Magn Reson Imaging 1999;10:223-232.

37. Daisne JF, Sibomana M, Bol A, et al. Tri-dimensional automatic segmentation of PET volumes based on measured source-to-background ratios: Influence of reconstruction algorithms. Radiother Oncol 2003;69:247-250.

38. Ollers M, Bosmans G, van Baardwijk A, et al. The integration of PET-CT scans from different hospitals into radiotherapy treatment planning. Radiother Oncol 2008;87:142-146.

39. Beaulieu S, Kinahan P, Tseng J, et al. SUV varies with time after injection in (18)F-FDG PET of breast cancer: Characterization and method to adjust for time differences. $\mathrm{J} \mathrm{Nucl} \mathrm{Med}$ 2003;44:1044-1050.

40. Eary JF, Mankoff DA. Tumor metabolic rates in sarcoma using FDG PET. $J$ Nucl Med 1998;39:250-254.

41. Harrer JU, Parker GJ, Haroon HA, et al. Comparative study of methods for determining vascular permeability and blood volume in human gliomas. J Magn Reson Imaging 2004;20: $748-757$.

42. Jackson A, Jayson GC, Li KL, et al. Reproducibility of quantitative dynamic contrast-enhanced MRI in newly presenting glioma. Br J Radiol 2003;76:153-162.

43. Walker-Samuel S, Leach MO, Collins DJ. Reference tissue quantification of DCE-MRI data without a contrast agent calibration. Phys Med Biol 2007;52:589-601.

44. Janssen MH, Ollers MC, van Stiphout RG, et al. Evaluation of early metabolic responses in rectal cancer during combined radiochemotherapy or radiotherapy alone: Sequential FDG-PETCT findings. Radiother Oncol 2010;94:151-155.

45. Burgman P, Odonoghue JA, Humm JL, Ling CC. Hypoxia-Induced increase in FDG uptake in MCF7 cells. $\mathrm{J} \mathrm{Nucl} \mathrm{Med}$ 2001;42:170-175.

46. Dierckx RA, Van de Wiele C. FDG uptake, a surrogate of tumour hypoxia? Eur J Nucl Med Mol Imaging 2008;35:15441549.

47. Busk M, Horsman MR, Jakobsen S, et al. Cellular uptake of PET tracers of glucose metabolism and hypoxia and their linkage. Eur J Nucl Med Mol Imaging 2008;35:2294-2303.

48. de Lussanet QG, Backes WH, Griffioen AW. Dynamic contrastenhanced magnetic resonance imaging of radiation induced therapy-induced microcirculation changes in rectal cancer. Int $J$ Radiat Oncol Biol Phys 2005;63:1309-1315. 